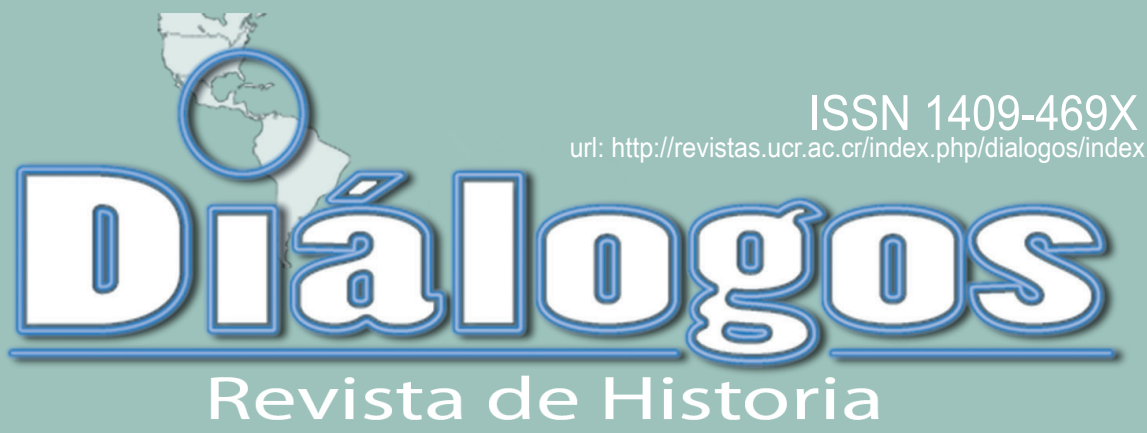

Escuela de Historia. Universidad de Costa Rica Vol. 15 No. 2 Setiembre 2014 - Enero 2015

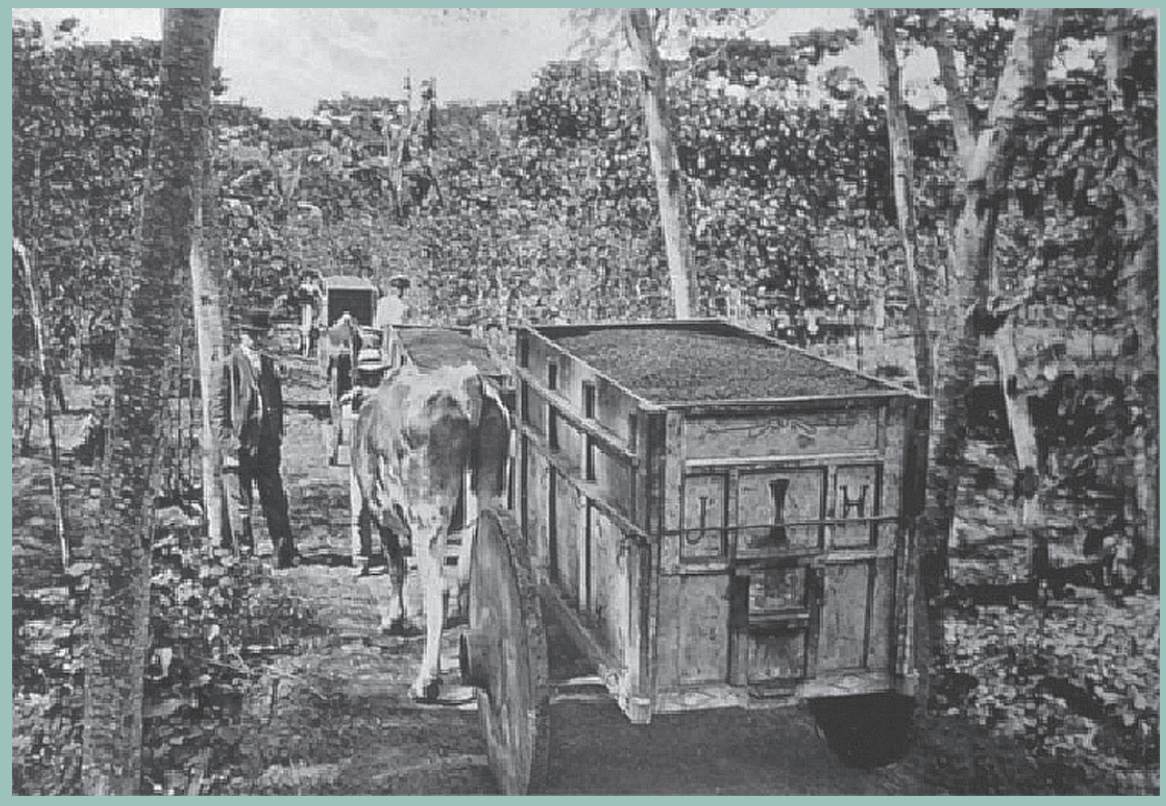

Director de la Revista: Dr. Juan José Marín Hernández juan.marinhernandez@ucr.ac.cr

Editor académico: Dr. David Díaz Arias - david.diaz@ucr.ac.cr Editor técnico: M.Sc. Marcela Quirós G. - marcela.quiros@ucr.ac.cr

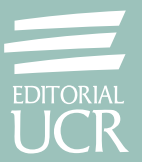


HISTORIA DE AMÉRICA LATINA 


\title{
POLÍTICA LEONCIO MARTÍNEZ: UN PERSONAJE QUE MARCÓ PAUTA EN LA DISIDENCIA
}

\author{
LEONCIO MARTÍNEZ: A CHARACTER THAT MARKED PATTERN IN DISSENT
}

Omaira Zambrano Roa

Alejandro González

\author{
Palabras claves \\ Leoncio Martínez, publicaciones, dictadura, historia política. \\ Keywords \\ Leoncio Martínez, political, dictatorship, publication.
}

Fecha de recepción: 7 de febrero, 2014 - Fecha de aceptación: 1 de junio 2014

\begin{abstract}
Resumen
Cuando se analiza la historia política de un país, se enfatiza en el estudio de sus períodos gubernamentales y en los partidos políticos, dentro de los cuales existen personajes que marcaron pauta en el desarrollo de la Nación. Durante la dictadura del general Juan Vicente Gómez (19081935) en Venezuela, uno de estos personajes característicos fue Leoncio Martínez, quien ostenta entre sus logros más reconocidos la fundación del semanario humorístico "Fantoches", junto a Francisco Pimentel (Job Pim). La investigación que se presenta es producto de la revisión hemerográfica y bibliográfica sobre el autor. Leoncio Martínez demostró ser un ciudadano como pocos dedicado a enaltecer su patria de diferentes maneras a través de sus labores, publicista, humorista, caricaturista y periodista. Entre los objetivos del presente artículo se encuentran el dar a conocer la valentía de un personaje que demostró su capacidad literaria, crítica y calidad humana en una época que requería periodistas organizados para disentir ante la situación de un país oprimido por la dictadura.
\end{abstract}

\begin{abstract}
When you view the political history of a country, there is emphasis on the study of their periods in government and political parties, but there are characters that mark developmental pattern of them in the Venezuelan case is Leoncio Martínez. One of his most famous work was the foundation of the weekly comedy puppet, and Francisco Pimentel (Job Pim) in 1923, which was director and frequent collaborator, made playful criticism and dislike the government in Leo and comment. With the acclaimed controversy at the time because the publication, the dictator ordered its immediate closure. In his work as a journalist also contributes to the writing of reports and opinion pieces in newspapers and magazines Venezuela as La Voz del Pueblo, El Cojo Ilustrado (1908), El Nuevo Diario, Magic Lantern and Pitorreos (1913). Next to Achilles Nazoa marked pattern within the genus. His life is difficult due to constant harassment, but this never stopped him. Among the objectives of this article are to present the courage of a character who showed his literary ability, critical and humanity in an era requiring journalists to dissent organized at the situation of a country oppressed by the dictatorship.
\end{abstract}


Antes de iniciar con el presente ensayo, es necesario destacar el hecho de que entre la prensa y el historiador hay una especie de alianza, por medio de la cual se nutre la historia. Como bien sabemos, es poco usual que exista una historia que no haya recurrido a la prensa como ingrediente de sus fuentes de investigación. En tal sentido, el estudio de los periódicos, de los profesionales que prestan servicio en los medios de comunicación escritos, de cuál ha sido su visión de mundo, del contexto del país en que se desenvuelven; entre otros elementos, representan una oportunidad de investigación muy interesante para cualquier historiador.

La importancia del presente análisis radica en el estudio de biografías de personajes, cuyas vidas constituyen un aporte para las futuras generaciones. Este ensayo pretende proporcionar la reseña biográfica de un periodista que sufrió en carne propia una de las dictaduras más largas que ha tenido Venezuela. Las revisiones bibliográficas y de hemeroteca serán fuentes de información que permitirán formar el soporte puntal de la producción escrita que se presentará a partir de la hermenéutica y la mayéutica.

Conocer el legado de Leoncio Martínez es la intención fundamental de este ensayo. Este autor se destaco dentro de las labores del periodismo, fue un insigne hombre de letras, periodista, dramaturgo y caricaturista; que dejó al descubierto en su obra el enfoque opositor que sostuvo ante los acontecimientos de la época. Así, marca pauta en el periodismo de opinión venezolano.

Martínez llegó a ser considerado un ciudadano ejemplar, debido a que sirvió de motivación a jóvenes cansados de ver a su patria consumida por la anarquía y el egocentrismo de un mandatario dictatorial. Su obra se caracterizó por ser una tribuna pública para disentir y criticar. Junto a Aquiles Nazoa selló un prototipo del género periodístico de su época

Una de sus labores más reconocidas fue la fundación del semanario humorístico "Fantoches", junto a Francisco Pimentel (Job Pim), en 1923. Fue director y colaborador frecuente de dicho semanario, así como también hacía críticas al gobierno en la sección "Leo y comento". Ante la aceptación y preferencia del público por la obra de Leoncio Martínez, -en adelante Leo, como le gustaba hacerse llamar-, el dictador Juan Vicente Gómez ordenó de inmediato el cierre de la publicación.

Es preciso señalar que dentro su tarea periodística, también contribuyó con la escritura de reportajes y artículos de opinión en periódicos y revistas venezolanas como: La Voz del Pueblo, El Cojo Ilustrado (1908), El Nuevo Diario, La linterna Mágica y Pitorreos (1913). A través de estos aportes se cimenta su valiente pluma, que ejemplariza cómo el coraje, los principios y ante todo, la verdad están por encima de cualquier ideología o corriente política. 
Fue perseguido por mantener siempre su crítica sobre el general instaurado como dictador. Durante el régimen, la intolerancia llegó al punto más álgido al cerrar cada uno de los medios libres e imparciales del país.

\section{LEONCIO MARTÍNEZ EN SU CONTEXTO HISTÓRICO}

Para la época del nacimiento de Leoncio Martínez gobernaba Ignacio Andrade, quien fue víctima de un alzamiento militar encabezado por el Mocho Hernández, y desde los Andes por Cipriano Castro, Diputado por Táchira. Hernández, convertido en caudillo, inicia la Revolución Restauradora, que logró la renuncia de Andrade. Un trabajo que alude a este presidente de manera más amplia es la biografía de "El Nacional" realizada por el historiador David Ruiz.

Posteriormente, Cipriano Castro llega al poder y trata de organizar una sociedad de fidelidades y recursos tangibles, el primer socio es su compadre: Juan Vicente Gómez, luego se fortalece con la adhesión de cientos de tachirenses, que no se hizo esperar. De esta forma, cruzando el río Táchira, los revolucionarios se enrumban en la empresa libertadora hacia Caracas, a la voz de "Vencer o Morir" (Bravo, 2004).

Después de cuatro meses de campaña, entran a Caracas el 22 de Octubre de 1899, con un nutrido ejército, que fue creciendo en el camino gracias a la adhesión de cientos de venezolanos a las tropas "Restauradoras". Según Bravo (2004) vencido ya en Tocuyito Elías Aular, Presidente de Estado, Castro toma posesión del gobierno con estas palabras: "Nuevos hombres, nuevos ideales y nuevos procedimientos”. Aunque en la práctica este lema no se aplicó con rigor.

Luego de dirimir pequeños alzamientos internos por parte de viejos caudillos, el General Cipriano Castro se afianza en la silla presidencial y encamina al país a una paz que se anunciaba estable.

Leoncio Martínez nació en Maripérez, Caracas, el 22 de diciembre de 1888, durante la época del gobierno de Ignacio Andrade, como se dijo anteriormente. Para este momento la sangre libertadora y artística se conjugan en la sangre nueva de Leo. Se sabe que su abuelo paterno luchó en la Guerra de Independencia. Por su parte, su vena artística la heredó de su abuelo materno Celestino Martínez, célebre pintor venezolano, de cuya obra da fe el periodista Oscar Yánez. Su padre, Don Juan Martínez, un incansable precursor de libertades, venido a menos, trabajaba en un escritorio de la Tesorería Nacional, entre tinta y papeles y desde allí participó en varios movimientos clandestinos que lo llevaron en distintas oportunidades a la cárcel. De esta manera llega a los 90 años, siempre de pie.

Sobre la niñez de Leo, Palenzuela (2006) cita: 
...aquellas horas largas que ustedes me ponían a hojear un volumen enorme, un suplemento ilustrado de El Correo de Ultramar, con grabados en acero y lecturas de guerra, exploraciones y cacerías, engendraron esta vida mía soñolienta e inmóvil, la costumbre de traer el mundo al cuarto, en vez de irlo a buscar bajo el sol, contra el aire, en la carretera, por el campo, en relación del músculo, sentado en la turca, con mi caja de creyones (p.14).

Son horas formidables de producción, de historia, de empeño infantil, de afición por los colores y las caricaturas. Allí se define su vocación, la vena artística le brota por sí misma.

Pérez (1981) reseña de Leo que, con motivo de la muerte de su padre, produce de su puño y letra un texto dedicado a él:

Con el alba del 19 de Abril del año 10, gritó: Libertad, acumulando códigos a guisa de bastón para que dispersaran los soldados de Oriente y viene a cerrar la fila el progenitor de este, el Teniente Coronel que llegara a Andalucía a personarse como alcalde de Cumaná, en nombre del Rey... ¡y el hijo le resultó republicano! (p. 22).

En el año de 1901, Leoncio Martínez sumaba la edad de 11 años. Se muda de Maripérez a un sitio más cercano a la ciudad, lleno de verdor y cada vez más aristocrático y se codea con las familias de más puro abolengo. Esto le sirvió para conocer a los miembros de esta clase social y repudiar las acciones que tomaban en contra del pueblo.

En otro orden de ideas, Leo tiene en su propia casa su escuela de arte. La herencia de su abuelo materno tangible en bocetos embaulados y en paisajes urbanos que adornan las paredes de su vivienda. Mientras tanto, un familiar más cercano, concretamente nos referimos a su hermano, dedica horas a la caricatura política, él observa y no duda en imitar esta practicar inmediatamente.

Asegura Pérez (1981), que el polifacético artista escribió en innumerables periódicos de circulación nacional con su nombre, iniciales o los seudónimos de "Luis Faskally", "Santiago de León", "L M", "Leo"; entre muchos otros. Este último lo usó toda la vida y fue el que lo hizo famoso.

Junto a su hermano "Raf", su gran mentor, inicia el recorrido por la prensa en 1900, estando aún muy joven, en la "Linterna Mágica”. En 1908 llega a la casa del "Cojo Ilustrado" y figura como uno de sus principales colaboradores. Posteriormente, publica en "El Constitucional". Bravo (2004) asevera que en la década de 1910 publica en "El Universal", "El pregonero", "La Revista", "Actualidades", "Venezuela Contemporánea" y "El Nuevo Diario", este último dirigido por Valle- 
nilla Lanz, uno de los intelectuales más respetados en el país, quien serviría como legitimador del régimen.

Es importante aclarar que la prensa, en la época de Gómez, estuvo muy vinculada a las predicas positivistas venezolanas y a su más fiel y celoso exponente: Vallenilla Lanz. Todos los periódicos en algún momento publicaron alguna información referente al Benemérito (como se le apodaba a Juan Vicente Gómez), a sus viajes o cualquier información de interés nacional. Fue el vínculo más poderoso para comunicar la información del régimen. Al respecto, cabe indicar que el sentido de la historia no es juzgar la actuación de los hombres y mujeres, sino más bien reconstruir su paso en el tiempo, aunque es difícil no tomar partido moral, sentimental o político por una posición, cuando de biografías se trata.

Por otro lado, Rafael Martínez, mejor conocido como Raf, seudónimo que lo hizo popular entre los lectores del semanario satírico y humorístico "La Linterna Mágica, favorito entre el público y dirigido por los hermanos Muñoz Tebar. En dicha publicación, en la cual plasmó sus más grandes caricaturas, Leo no tarda en seguir los pasos de su hermano y con su ayuda, ilustra varias páginas de este órgano de divulgación con sus dibujos. En 1902, este medio siente el peso de la ley dictatorial, cuando lo sacan de circulación por órdenes del Cabito (Guerra, 2004).

A partir de este momento, Leo Martínez comienza a dibujar para "La Voz del Pueblo", pero una situación desdichada ataca el seno de la familia. Raf es enviado a prisión por órdenes del caudillo, acusado de contestarle airadamente a un personero del régimen Restaurador. A su vez, durante los gobiernos de Juan Vicente Gómez y Eleazar López Contreras, Leo fue confinado a "La Rotunda" en varias ocasiones, por sus fuertes intervenciones políticas en Venezuela.

En este momento, el artista debe hacer un paréntesis en su vida de dibujante. Sin embargo, como figura polifacética, la música fue otra de las pasiones de Martínez. Compuso en diversas ocasiones letras de corte popular tan emblemáticas como "Dama Antañona" y "La Musa del Joropo".

En 1911, viaja a Puerto Rico, donde se residencia por un largo período. Palenzuela (2006) explica que la motivación de este exilio es básicamente la persecución que sufría el periodista por parte de los órganos represores del Estado. Durante su ausencia siguió escribiendo en "El Universal", enviaba sus artículos desde San Juan. En 1912 fue uno de los principales promotores de la creación del Círculo de Bellas Artes.

Leoncio Martínez fue perseguido por "La Sanidad", como era conocida la policía de la época. Es atrapado y enviado nuevamente a "La Rotunda". Según Pérez (1981) ahí dentro escribe los siguientes versos: 
Estoy pensando en exilarme

en marcharme lejos de aquí

a tierra extraña donde goce

las libertades de vivir...

(Martínez, 1919, citado por Pérez, 1981, p.46).

Sin embargo, nunca se doblegó. Su valiente pluma sirvió y sirve de ejemplo en la actualidad. Es muestra de coraje, de principios y de verdad, la cual está por encima de cualquier ideología y/o corriente política. De este modo, resulta muy importante conocer el momento político-social que lleva a este señor de las letras a oponerse fervientemente a un gobierno dictatorial. Tal como lo indagaremos a continuación.

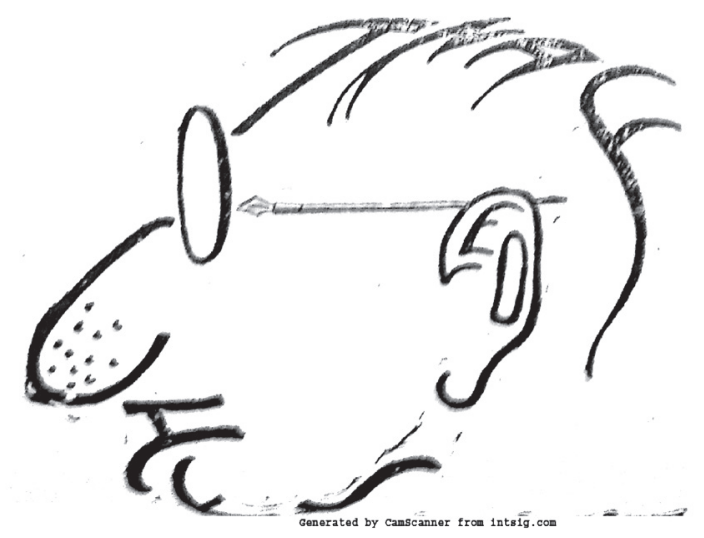

Figura 1: Autorretrato. Fuente: La Huella de Leoncio Martínez. (Pérez, 1981). La Huella de Leoncio Martínez. UCV. (Caricatura) Reproducción permitida por la autora y utilizada en el trabajo de grado de Alejandro González.

Luego de la renovación que sacudió a Venezuela con la llegada al poder del General Gómez, también surge en el Instituto Nacional de Bellas Artes un grupo de estudiantes y discípulos del maestro Antonio Herrera Toro, quienes protestan por la nueva dirección que toma la institución. Todos fueron expulsados y el instituto sometido a severa disciplina. Para ese entonces "L M" (así firmaba Leoncio Martínez) contaba con apenas veinte años de edad y con una breve pasantía por la academia. Para entonces ya era conocido por sus caricaturas y peculiar humor.

En sus inicios, sus dibujos eran de corte antiimperialista, estilo y postura que mantuvo por mucho tiempo, y que también fundamentaron sus poemas. 

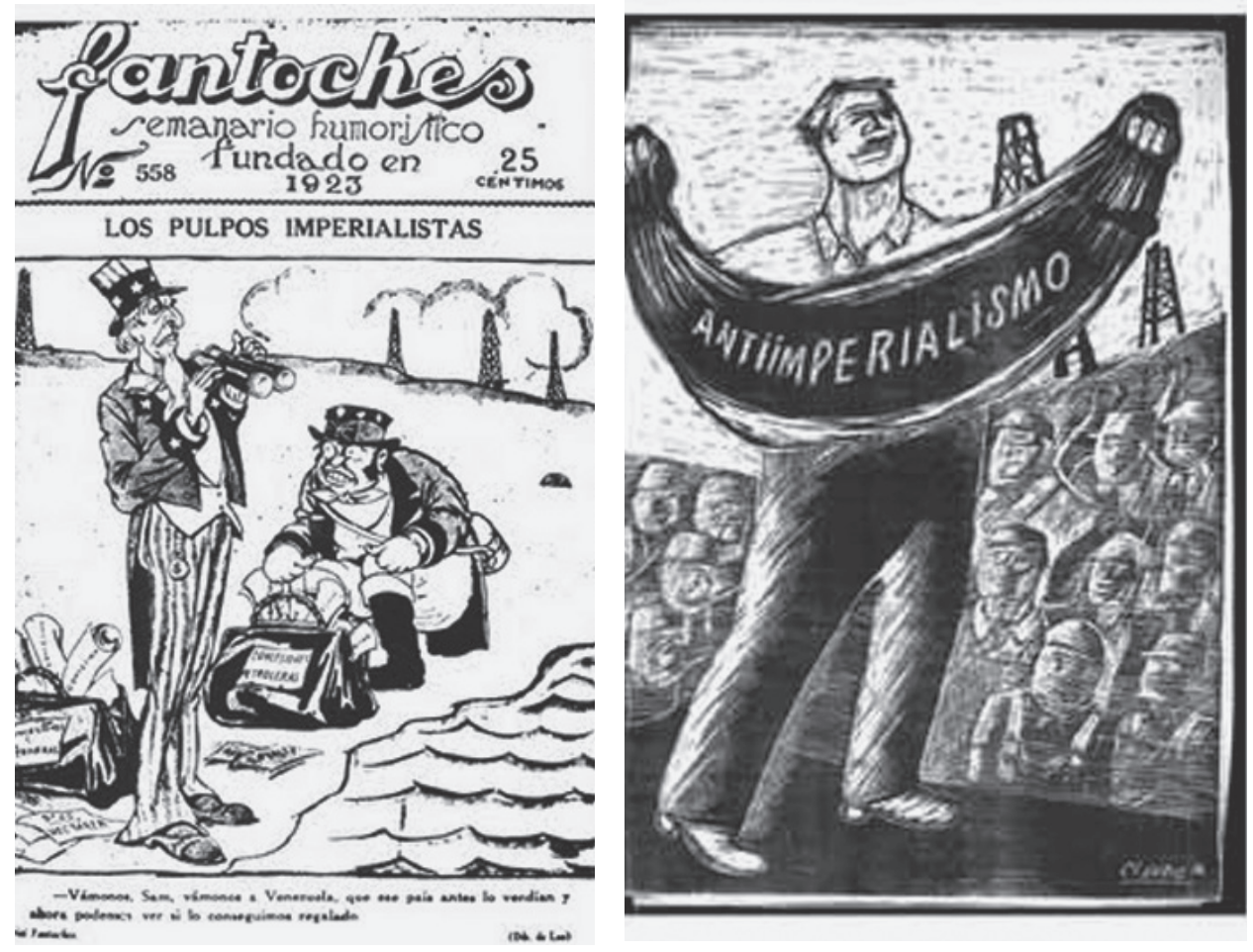

Figura 2. En las caricaturas de Leo, se puede observar la crítica al imperialismo de Estados Unidos y Gran Bretaña, naciones que controlaban las empresas petroleras, desde el periodo de gobierno de Juan Vicente Gómez, pasando por las etapas de mando presidencial de Eleazar López Contreras, hasta llegar a Isaías Medina Angarita. Fuente: Hemeroteca Nacional. Colección Fantoches (Caricaturas).

Claramente, Martínez hacía alusión a las empresas transnacionales que estaban encargadas de la explotación y demás actividades de la industria petrolera. Como se sabe, durante el gobierno de Juan Vicente Gómez, se favoreció con contratos leoninos a las empresas petroleras. Estas cancelaban un porcentaje muy bajo de regalías al Estado y así obtenían amplios beneficios La legislación en esta materia se mantuvo igual durante el gobierno de Eleazar López Contreras.

En otro orden de ideas, Martínez también fue un publicista destacado. Sus novedosos y luminosos anuncios publicitarios decoraban cualquier esquina caraqueña, con bombillos, luces pintadas y telas texturizadas, que cambiaban cada mes para lograr diversos efectos de iluminación. Las salas de teatro de la Caracas de antaño gozaban de la exquisita decoración del artista.

Luego de varios años, ganándose la vida en el mundo de la publicidad, el 19 de abril de 1923 funda el semanario humorístico de intereses generales "Fantoches". Como se mencionó anteriormente, en su primera etapa sirve de instrumento de expresión, hasta el año de 1933. Pérez (1981) puntualiza que: “...cuando es clausurado por sus criticas a los altos funcionarios, fue tanta la popularidad que 
tuvo, que los vendedores preferían pagar las altas multas impuestas por el aparato represor del Estado que dejar de vender 'Fantoches'..." (P. 25).

En el año 1928 comienzan a sentirse los primeros síntomas de cambios en la vida venezolana. La política y la cultura van unidas, con los estudiantes revueltos, la publicación se convierte en vanguardia, en válvula de las altas expectativas sociales y culturales.

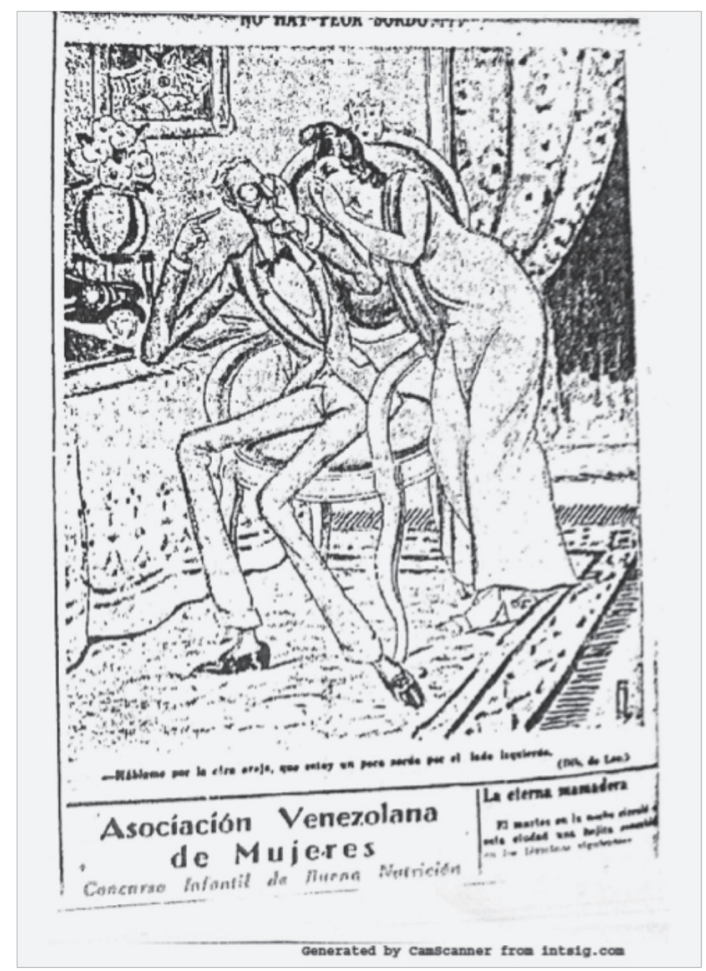

Figura 3. Presidente López Contreras fue objeto de sus caricaturas. Fuente Fantoches en la Biblioteca Nacional de Venezuela

\section{CARICATURISTA}

Corría el año de 1928 cuando, con ocasión de la celebración de la Semana del Estudiante, pautada en aquellas fechas conjuntamente con la celebración de los carnavales, saltó a la palestra pública una generación estudiantil que luego sería conocida como la Generación del 28.

Según Silva (1976) bastó el "acto irrespetuoso" de Guillermo Prince Lara, quien rompió una lápida en honor a Juan Vicente Gómez, algunas palabras encendidas de los entonces estudiantes Rómulo Betancourt, Jóvito Villalba y Joaquín 
Gabaldón Márquez, sumadas a un duro poema leído por Pío Tamayo, antiguo exiliado y perseguido político, en la coronación de la reina del carnaval estudiantil "Beatriz I"; para que la maquinaria represiva de Juan Vicente Gómez les considerase subversivos y dirigiera contra ellos todas sus fuerzas de miedo y de oprobio. Por esta razón se canceló inmediatamente la celebración y se mandó a Tamayo y a los demás líderes estudiantiles a la cárcel de La Rotunda.

Dice textualmente Silva (1976): "En un gesto que verdaderamente marcó época, ante la injusticia desatada por el régimen Gomecista, el resto de los compañeros estudiantiles se entregó también a las autoridades. En total, doscientas catorce personas fueron encarceladas en el Castillo de Puerto Cabello. Esto generó una indignación tal a nivel nacional que se materializó en protestas generalizadas, las cuales lograron la liberación de los estudiantes al cabo de doce días" '(p.78).

Con el objeto de obtener la libertad de los compañeros detenidos debido al intento de sublevación del 7 de abril, un grupo de estudiantes redactó en octubre de 1928 un documento dirigido a Juan Vicente Gómez, con el propósito de que reconsiderara su severa medida. Silva (1976) expresa que: "No obstante, Gómez no sólo desatiende sus demandas, sino que manda capturarlos, siendo conducidos, en medio de protestas públicas, junto a cerca de 200 estudiantes, a las colonias de Araira, donde se construía un tramo carretero, en el que deberían cumplir trabajos forzados" (p. 50).

La importancia en la historia contemporánea de Venezuela de esta Generación del 28 se fundamenta en tres aspectos elementales: en primer lugar, un caudillo como Juan Vicente Gómez habituado a dirimir los conflictos políticos en el campo de batalla, se enfrenta a un grupo de estudiantes que, actuando como colectivo, plantea una lucha en un ámbito desconocido por Gómez, y en general por los caudillos del siglo XIX: la ciudad. En otras palabras, a partir de este momento las batallas políticas del siglo XX se desarrollarán en las ciudades, mediante huelgas generales, paros, boicots, entre otros métodos de protesta popular.

En segundo lugar, el carácter colectivo del movimiento de 1928, expresado en la propia denominación de "Generación", formará parte de otro importante elemento de ruptura con la historia política del siglo XIX: la despersonalización del poder. Es por eso que, pese a la cantidad de líderes presentes en los sucesos de 1928, tales como Rómulo Betancourt, Jóvito Villalba, Miguel Otero Silva, Raúl Leoni y Juan Bautista Fuenmayor; ninguno tuvo un protagonismo especial, sino que predominó la unidad del grupo sobre cualquier individualidad. Esto produjo el adelanto de una de las principales características de las organizaciones políticas del siglo XX: la disciplina partidista.

De esta manera, con los jóvenes estudiantes del 28 se introdujeron nuevas ideologías: socialismo, marxismo y democracia; las cuales no consiguieron la aceptación de los viejos líderes, como es el caso de Gómez. 
En el año de 1933, por desacato a la autoridad y caso omiso a las advertencias de censura, el semanario "Fantoches" fue clausurado por un tiempo,

Posteriormente, con la muerte del Presidente Juan Vicente Gómez en el año 1935, se inician cambios en la política venezolana. Transformaciones apreciables en algunos de los medios de circulación nacional, como es el caso de "El Universal". Gutiérrez (2001) cita:

\author{
ANOCHE A LAS 11:45 FALLECIÓ EN MARACAY EL BENEMERITO \\ GENERAL JUAN VICENTE GÓMEZ, PRESIDENTE DE LA Repú- \\ blica. El Ejecutivo Federal, el Ejército de la Nación, el Poder Judicial, demás \\ organismos públicos del país, interpretan el sentimiento ciudadano en esta \\ hora de duelo de la República al tributar imponentes homenajes de justicia a la \\ memoria del ilustre varón desaparecido (p. 96).
}

Pérez (1981) explica: "Después de la muerte de Juan Vicente Gómez hay un cambio en la caricatura de Leo, la libertad de expresión todavía muy limitada" (p. 29). Esto le permitió a Martínez dibujar una serie de personajes y expresar ideas que hasta el momento no había podido pronunciar abiertamente. Entonces, este fue el momento cumbre para que los ciudadanos pudieran constatar que las caricaturas eran de su autoría, sin necesidad de adivinar.

El cierre definitivo de "Fantoches" se dio durante la huelga petrolera del 37, durante el gobierno de López Contreras. Pérez (1981) asegura que:

...cuando en actitud solidaria con la masa trabajadora, trae severos problemas
al semanario. Personeros del gobierno se acercan a Leo para negociar la conti-
nuidad del periódico, pero él fiel a sus principios rechazó todas las ofertas, y
así Mibelli firma la resolución de suspensión indefinida del semanario (p. 38).

En las siguientes citas se evidencia la censura y la represión selectiva del Gobernador de turno. El autor Palenzuela (2006) indica: "El post gomecismo es un período convulsionado, y Fantoches y Leo nuevamente llevaron la peor parte, en Junio de 1937. El Gobierno del Distrito Federal señala que las páginas del humorista están dedicadas a subvertir el orden" (p.78). Un fragmento de la noticia que fue publicada en "El Universal”, citada por Palenzuela (2006) manifiesta: “...y no otra cosa ha venido haciendo, de manera sistemática, el semanario Fantoches, se suspende indefinidamente la publicación, por órdenes del Gobernador..." (p. 89).

El 14 de Octubre de 1941 fallece en Caracas Leoncio Martínez, a causa de una tuberculosis que lo aquejaba desde el año 1924. En una nota en primera página "El Heraldo" lo reseña así: "Pierde Venezuela un prominente representante de las 
letras nacionales, el ingenio de su lápiz luchó con decisión por las reivindicaciones civiles". Estas palabras resumen el talante democrático y combativo de Leo.

En la tarjeta del entierro suscriben sus amigos Leopoldo Ayala Michelena, Andrés Eloy Blanco, Rómulo Betancourt, Luis Beltrán Prieto Figueroa, Monseñor Pellín, Jóvito Villalba, Francisco Pimentel; entre una larga lista de personalidades que hacían vida activa en diferentes instancias del país. La lista da una idea de la estimación que le tenían a Leo; a este llamado también se unieron estudiantes, federaciones, consejo legislativo y personas de todos los rincones de Venezuela, quienes querían darle el último adiós. En los anales del periodismo, se recuerda la multitud que acompañó a Gardenio en brazos hasta el Cementerio General del Sur, este fue un día que marcó un hito en la historia nacional.

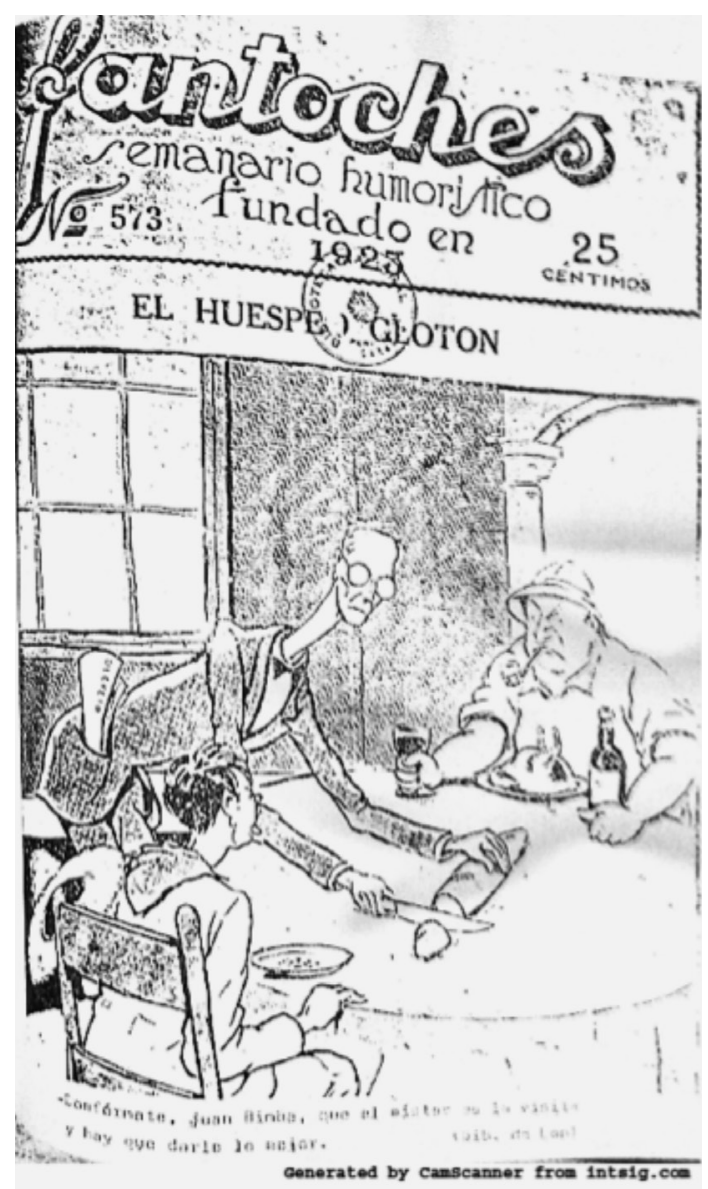

Figura 4. Las trasnacionales y el presidente López Contreras, Fuente Fantoches en la Biblioteca Nacional de VenezuelaFuente: Hemeroteca Nacional, Colección Fantoches (Caricaturas). 
Palenzuela (2006) recoge este momento de la siguiente manera: "Luchó en el campo de la prensa, fue caricaturista, fue escritor, en más de una ocasión hubo grandes disputas y polémicas, pero no es hora de criticar, sino de recordarlo" ( $p$ 100).

El criollismo y la caraqueñidad son epítetos que definen a este personaje, dedicado en cuerpo y alma a la libertad y a su gente. Como hemos podido apreciar, cruzó diferentes campos, como la poesía, la publicidad, el teatro, la pintura, y muchas otras facetas, que lo definen como un ciudadano ejemplar.

Con todo lo anteriormente expuesto, con respecto al itinerario por las páginas de la vida de Leoncio Martínez, se genera otra lectura de la llamada "historia negra", que alude al gobierno de un tirano y analfabeta, que conducía el país sin que nadie le hiciera frente. Sin embargo, venezolanos como Martínez, lo enfrentaron y le dieron sentido a la historia, pues lucharon hasta su último día en esta tierra en contra del yugo opresor.

Comprobamos de esta manera que, ni la historia es lineal, ni está del todo exenta de errores. En consecuencia, no podemos seguir juzgando con "la varita del bien y el mal", debemos tratar de reconstruirla y aprender de ella, por medio de los ojos de ilustres personajes, como aquellos que pertenecieron a la generación del 28.

Un ciudadano como pocos, dedicado a enaltecer su patria de diferentes maneras. Digno de recordar cada día por sus múltiples facetas: músico, dramaturgo, publicista, humorista, caricaturista y periodista.

Leoncio dedicó su vida por completo a dar ejemplo de ciudadanía, se caracterizó por ser una tribuna pública para disentir; fue un pionero en su rama periodística, el género de opinión, tan criticado durante su época. Por esta razón, es considerado uno de los mayores exponentes del periodismo crítico en Venezuela.

\section{CITAS Y NOTAS}

1 Al poco tiempo de la liberación de los estudiantes, se produce un acercamiento entre algunos de éstos (Juan José Palacios, Francisco Rivas Lázaro, Fidel Rontondaro y Germán Tortosa, entre otros) con jóvenes oficiales del Ejército, entre quienes se encontraba el hijo Eleazar López Contreras. Asegura Castellanos (1978) “...con la finalidad de planificar un golpe de Estado que debía ejecutarse el 7 de abril de 1928, pero que fue debelado antes de producirse...". 


\section{REFERENCIAS}

Añez, B. (2003). La Producción Gráfica y las Historietas de Leoncio Martínez de 1900 a 1941 en el Contexto Social Venezolano. (Trabajo de grado publicado). Venezuela: Universidad Central de Venezuela.

Arévalo, A. (1932). Breve revisión de Leo y su libro Mis Otros Fantoches. Venezuela: El Universal.

Bravo, M. (2004). La Intelectualidad del Gomecismo. (Trabajo de grado no publicado). Venezuela: Universidad de los Andes.

Fernández, C. y Hernández, S. (1991). Metodología de la Investigación. México: Editorial Planeta.

Fundación Polar. (1997). Diccionario de Historia de Venezuela. Venezuela: Editorial Ex Libris.

Guerra, G. (2004). Pioneros del Periodismo Venezolano en los Años 40, 50, 60. (Trabajo de grado no publicado). Venezuela: Universidad Católica Santa Rosa.

Hemeroteca Nacional (1923, 1924, 1925, 1927, 1928, 1930, 1936, 1937, 1938, 1941) Colección de Fantoches. Venezuela: Hemeroteca Nacional.

Hemeroteca Nacional $(1937,1941)$ Colección de La Esfera. Venezuela: Hemeroteca Nacional

Hemeroteca Nacional. (1927-1938). Colección de El Nuevo Diario. Venezuela: Hemeroteca Nacional.

Hemeroteca Nacional. (1931-1938). Colección de El Universal. Venezuela: Hemeroteca Nacional.

Mujica, H. (1994). La Prensa Venezolana en el Siglo XX. Venezuela: Fundación Neuman.

Nazoa, A. (1959). Los Dibujos de Leo. Venezuela: Editorial Pensamiento vivo.

Palenzuela, J. (1980). Mis otros Fantoches. Venezuela: Editorial Seleven

Palenzuela, J. (1983). Leoncio Martínez, Crítico de Arte. Venezuela: Academia Nacional de Historia.

Palenzuela, J. (2006). Biografía de Leoncio Martínez. Venezuela: Editorial El Nacional 
Pérez, O. (1981). La Huella de Leoncio Martínez. (Trabajo de grado publicado). Venezuela: Universidad Central de Venezuela.

Pestana, E. (2006). Rafael Arévalo González Defensor de la Patria. (Trabajo de grado no publicado). Venezuela: Universidad Católica Santa Rosa.

Velásquez, R. (1989). Confidencias Imaginarias de Juan Vicente Gómez. (10 ed.). Venezuela: Editorial Centauro.

Yánez, O. (1992). Memorias de Armandito, Historias Ocultas, Trágicas y Divertidas de la Vida Venezolana. Venezuela: Editorial Planeta.

\section{SOBRE LOS AUTORES}

Omaira Zambrano Roa: Universidad Simón Bolívar. Venezuela. Profesora en Ciencias Sociales. Mención historia. Maestría en Educación.. Profesora contratada en la USB. Venezuela

Alejandro González: Comunicador Social graduado de la UCSAR. Crítico social e investigador. Trabajó en la alcaldía del estado Miranda en Venezuela. 